\title{
EFICIÊNCIA FOTOSSINTÉTICA E CRESCIMENTO DE GENÓTIPOS DE ABACAXIZEIRO CULTIVADOS IN VITRO EM DIFERENTES QUALIDADES DE LUZ, TIPOS DE FRASCO DE CULTIVO E CONCENTRAÇÕES DE SACAROSE ${ }^{1}$
}

\author{
TARCISIO RANGEL DO COUTO ${ }^{2}$, JEFFERSON RANGEL DA SILVA ${ }^{3}$, ALENA TORRES NETTO $^{4}$, \\ VIRGINIA SILVA CARVALHO ${ }^{4}$, ELIEMAR CAMPOSTRINI $^{5}$
}

RESUMO-Foram otimizados os protocolos de micropropagação das cultivares de abacaxizeiro 'Vitória' e 'IAC Fantástico', bem como as respostas fotossintéticas e de crescimento destes genótipos à alteração do ambiente de cultivo in vitro. Para as duas cultivares, os tratamentos foram dispostos em DIC, com seis repetições e cinco plantas por repetição, em um esquema de parcelas subsubdivididas, constituídas de qualidade de luz (branca e vermelha), tipo de frasco de cultivo (fechado e ventilado) e concentração de sacarose no meio de cultivo (15 e $30 \mathrm{~g} \mathrm{~L}^{-1}$ ). A avaliação foi feita após 40 dias de cultivo in vitro. Nas condições deste estudo, não houve assimilação fotossintética do carbono. Essa não assimilação foi associada ao comprometimento bioquímico e sem comprometimento na eficiência fotoquímica. A presença da sacarose pode ser considerada o fator responsável pela não assimilação do $\mathrm{CO}_{2}$. Em comparação à cv. IAC Fantástico, a cv. Vitória apresentou maior crescimento devido à maior absorção de carbono via sacarose adicionada ao meio de cultivo.

Termos para Indexação: 'Vitória', 'IAC Fantástico', micropropagação, Ananas comosus, ventilação.

\section{PHOTOSYNTHETIC EFFICIENCY AND GENOTYPES GROWTH OF PINEAPPLE CULTIVATED IN VITRO IN DIFFERENT QUALITIES OF LIGHT, GROWING JAR TYPES AND CONCENTRATION OF SUCROSE}

\begin{abstract}
Protocols for the micropropagation of pineapple cv. Vitória and cv. IAC Fantástico were optimized, as well as the photosynthetic and growth responses of these genotypes in response to changing the in vitro environment. For the two cultivars, treatments were arranged in a completely randomized design, with six repetitions and five plants per repetition, in a sub plots subdivided, made up of light qualities (white and red), types of culture vessels (closed and ventilated) and sucrose concentrations in the growth medium ( 15 and $30 \mathrm{~g} \mathrm{~L}^{-1}$ ). The evaluation was made after 40 days of in vitro culture. Under the conditions of this study there was no photosynthetic carbon assimilation. This non-assimilation was associated with biochemical compromises rather than photochemical efficiency. The presence of sucrose should be the factor responsible for non- $\mathrm{CO}_{2}$ assimilation. The cv. Vitória showed higher growth than the cv. IAC Fantástico due to the higher carbon absorption via sucrose.
\end{abstract}

Index terms: 'Vitória', 'IAC Fantástico', micropropagation, Ananas comosus, ventilation.

\footnotetext{
'( Trabalho 167-13). Recebido em: 05-042013. Aceito para publicação em: 12-12-2013.

${ }^{2}$ Eng. Agr., Mestre em Genética e Melhoramento de Plantas. Universidade Estadual do Norte Fluminense Darcy Ribeiro (UENF), Centro de Ciências e Tecnologias Agropecuárias (CCTA), Laboratório de Melhoramento Genético Vegetal (LMGV), Setor de Fisiologia Vegetal. E-mail: tarcisiorcouto@yahoo.com.br

${ }^{3}$ Eng. Agr., Mestrando em Produção Vegetal. UENF/CCTA/LMGV, Setor de Fisiologia Vegetal. E-mail: jefferson-rangel@hotmail. com

${ }^{3}$ Eng. Agr., Doutora em Produção Vegetal. Pós-doutoranda FAPERJ. UENF, Centro de Biociências e Biotecnologia (CBB), Laboratório de Biologia Celular e Tecidual (LBCT). E-mail: alenanetto@msn.com

${ }^{4}$ Professora Doutora. UENF/CCTA, Laboratório de Fitotecnia (LFIT). E-mail: virginia@uenf.br ${ }^{5}$ Professor Doutor. UENF/CCTA/LMGV, Setor de Fisiologia Vegetal. E-mail: campost@uenf.br
} 


\section{INTRODUÇ̃̃O}

O abacaxizeiro (Ananas comosus (L.) Merril) é uma planta herbácea, perene, e pertencente à família Bromeliaceae. No Brasil, as cultivares de abacaxizeiro mais plantadas são 'Pérola' e 'Smooth Cayenne', e ambas são suscetíveis à fusariose, principal problema fitossanitário no País. Algumas soluções para evitar essa doença estão relacionadas ao plantio de mudas sadias e frequentes pulverizações com fungicidas. No entanto, a utilização de cultivares resistentes é o método mais eficiente e econômico para o controle da doença (CABRAL et al., 2009). As cultivares Vitória e IAC Fantástico são resistentes a fusariose, sendo o genótipo 'Vitória' um híbrido originado do cruzamento entre 'Primavera' $x$ 'Smooth Cayenne' (VENTURA et al., 2009) e 'IAC Fantástico' um híbrido do cruzamento entre 'Tapiracanga' x 'Smooth Cayenne' (SPIRONELLO et al., 2011).

A propagação comercial do abacaxizeiro é vegetativa, e o método convencional de propagação é feito por meio de mudas formadas a partir de brotações laterais da planta, denominadas filhote, filhote-rebentão ou rebentão, o que contribui para a disseminação de doenças e pragas. A micropropagação surge como uma alternativa bastante promissora. $\mathrm{Na}$ micropropagação convencional (MC), as plantas são cultivadas in vitro, em frascos sem trocas gasosas, com alta umidade do ar, baixa luminosidade e com a utilização de açúcares no meio de cultura como fonte de carbono e energia (KOZAI; KUBOTA, 2001).

Devido às condições da $\mathrm{MC}$, as plantas podem apresentar alterações anatômicas e metabólicas que as tornam organismos heterotróficos. Estas alterações podem impossibilitar que a maquinaria fotossintética opere normalmente in vitro. Por isso, algumas alterações no cultivo in vitro (cultivo fotomixotrófico), como a redução da concentração de sacarose do meio de cultura, a ventilação dos frascos de cultivo e a elevação da qualidade e da intensidade da luz podem estimular a capacidade fotossintética das plantas nestas condições, e assim produzir mudas mais rústicas e com melhor adaptação às condições ex vitro (aclimatização) (XIAO; KOZAI, 2004; FUENTES et al., 2007; DAMIANI; SCHUCH, 2008). Diante do exposto, esta pesquisa teve como objetivo buscar a otimização da micropropagação do abacaxizeiro cvs. Vitória e IAC Fantástico, relacionadas à capacidade fotossintética, às relações hídricas e ao crescimento, por meio da alteração na qualidade de luz, no tipo de frasco de cultivo e na concentração de sacarose no meio de cultivo in vitro.

\section{MATERIAL E MÉTODOS}

O experimento foi realizado em Campos dos Goytacazes - RJ, na Unidade de Pesquisa em Ecofisiologia/Fotossíntese de Plantas in vitro, situada no Setor de Fisiologia Vegetal do Laboratório de Melhoramento Genético Vegetal - UENF. Foram utilizadas brotações das cultivares de abacaxizeiro 'Vitória' e 'IAC Fantástico' já estabelecidas in vitro e na última fase de multiplicação. As brotações de 'Vitória' foram provenientes do Laboratório BIOMUDAS, Venda Nova do Imigrante - ES, e as brotações de 'IAC Fantástico', da SBW do Brasil Agrifloricultura, Holambra - SP. Para a montagem do experimento, sob condições de câmara de fluxo laminar, foram retiradas as folhas com um corte transversal próximo à base das brotações e, em seguida, foram colocadas cinco brotações em cada frasco do tipo baby food contendo $40 \mathrm{~mL}$ de meio de cultura. O meio para o enraizamento foi composto pelos sais de MS e as vitaminas de White (MURASHIGE; SKOOG, 1962), $100 \mathrm{mg}$ $\mathrm{L}^{-1}$ de mioinositol, $2,7 \mu \mathrm{mol} \mathrm{L}^{-1}$ de ANA (ácido naftalenoacético), solidificado com $8 \mathrm{~g} \mathrm{~L}^{-1} \mathrm{de}$ ágar bacteriológico $\operatorname{Vetec}^{\circledR}, \mathrm{pH}$ ajustado para 5,7 e autoclavado por 20 minutos a $1,0 \mathrm{~atm}$ e $121{ }^{\circ} \mathrm{C}$. Neste meio MS, e de acordo com o tratamento aplicado, foi adicionada sacarose nas concentrações de 15 e $30 \mathrm{~g} \mathrm{~L}^{-1}$.

Para as duas cultivares, o delineamento experimental foi o inteiramente casualizado, com seis repetições, com cinco plantas por repetição, em um esquema de parcelas sub-divididas, tendo nas parcelas dois tipos de luz (lâmpadas fluorescentes brancas OSRAM ${ }^{\circledR}$ e lâmpadas vermelhas $\mathrm{SCT}^{\circledR}$ T8-GL), nas subparcelas dois tipos de frascos de cultivo in vitro (fechado e ventilado), com duas concentrações de sacarose $\left(15\right.$ e $\left.30 \mathrm{~g} \mathrm{~L}^{-1}\right)$. Tanto para o sistema fechado como para o sistema ventilado, a unidade experimental foi constituída de um frasco grande $(2,2 \mathrm{~L})$, e, neste frasco, foram colocados quatro frascos menores abertos do tipo baby food - dois frascos com a cv. Vitória e dois frascos com a cv. IAC Fantástico, um com $15 \mathrm{~g} \mathrm{~L}^{-1} \mathrm{e}$ outro com $30 \mathrm{~g} \mathrm{~L}^{-1}$ de sacarose. O sistema ventilado (frascos maiores) adotado foi o proposto por Campostrini et al. (1999). O fluxo de ar injetado no frasco de cultura ventilado foi de aproximadamente $15 \mathrm{~mL} \mathrm{~min}^{-1}$, com uma concentração de $\mathrm{CO}_{2}$ de $380 \mathrm{ppm}$ (proveniente do meio externo ao laboratório). Na vazão de 15 $\mathrm{mL} \min ^{-1}$, o ar do frasco de cultivo de $2,2 \mathrm{~L}$ era renovado a cada 2 h $45^{\prime}$. No sistema fechado, os frascos maiores $(2,2 \mathrm{~L})$, contendo os frascos menores, foram hermeticamente fechados com tampa e filtro 
de PVC, sem nenhuma troca gasosa com o ambiente externo. A sala de cultivo foi mantida a $27 \pm 2{ }^{\circ} \mathrm{C}$, com temperatura média de $25,6^{\circ} \mathrm{C}$ e umidade relativa média de $76,6 \%$, fotoperíodo de $16 \mathrm{~h} 8$ (luz:escuro), com fluxo de fótons fotossintéticos das lâmpadas brancas e das lâmpadas vermelhas em torno de 85 $\mu \mathrm{mol} \mathrm{m} \mathrm{m}^{-2} \mathrm{~s}^{-1}$. O déficit de pressão de vapor médio do ar (DPV) injetado nos frascos ventilados foi de 1,17 KPa. A avaliação da distribuição do espectro da radiação luminosa emitida pelas lâmpadas foi feita com auxílio do aparelho Ocean Optics ${ }^{\circledR}$ (USB 2000+RAD, USA).

Aos 40 dias após a imposição dos tratamentos in vitro, foi feita a medida da massa da matéria fresca (MFT) (pesagem individual das mudas em balança analítica). Para a massa da matéria seca (MST), efetuou-se a secagem das mudas em estufa a 70 ${ }^{\circ} \mathrm{C}$, por 48 horas, e, após, procedeu-se à pesagem individual em balança analítica. Para a determinação da capacidade fotossintética das mudas, foram feitas avaliações relacionadas à eficiência fotoquímica e às trocas gasosas. $\mathrm{Na}$ avaliação da eficiência fotoquímica, o rendimento quântico máximo do fotossistema II (PSII) $\left(\mathrm{F}_{\mathrm{v}} / \mathrm{F}_{\mathrm{m}}\right)$ e o photosynthetic index (PI) foram determinados na folha mais desenvolvida por meio do fluorímetro não modulado, modelo Pocket PEA Chorophyll Fluorimeter ${ }^{\circledR}$ (Hansatech Instruments - King's Lynn, Norfolk). Durante as medidas, foi utilizada uma pinça para a adaptação dos cloroplastos ao escuro, para que todos os centros de reação do fotossistema II (PSII) adquirissem a condição de "abertos", e a perda de calor fosse mínima (STRAUSS et al., 2006). As medidas foram realizadas entre 08 e $12 \mathrm{~h}$. A taxa fotossintética líquida foi determinada colocando-se uma muda inteira (5 $\mathrm{cm})$ na câmara de $250 \mathrm{~mL}$ do medidor portátil de trocas gasosas LI-6200 ${ }^{\circledR}$ (LI-COR, Lincoln, NE, USA). Estas medições foram feitas em condições de laboratório, utilizando luz artificial por meio de LEDs vermelhos a uma intensidade de $300 \mu \mathrm{mol} \mathrm{m} \mathrm{m}^{-2} \mathrm{~s}^{-1}$. A estimativa de intensidade de cor verde foi avaliada por meio do medidor portátil de clorofila SPAD-502 Chlorophyll Meter ${ }^{\circledR}$ (Minolta, Japão), sendo feitas três leituras em cada folha amostrada. Os dados foram submetidos à análise de variância, e as médias referentes às interações foram comparadas pelo teste de Tukey, a 5\% de probabilidade. As análises estatísticas foram feitas com o uso do software SAS ${ }^{\circledR}$ (Statistical Analysis System, 2003).

\section{RESULTADOS E DISCUSSÃO}

A partir da análise de variância, constatou-se que, independentemente da cultivar, o fator sacarose não apresentou significância para nenhuma das variáveis analisadas (dados não mostrados). Sendo assim, esse fator foi desconsiderado, e realizou-se uma análise de variância considerando a parcela como luz, o tipo de frasco de cultivo como subparcela e o genótipo como subparcela. A interação entre luz e genótipo mostra diferenças significativas, com relação às variáveis $\mathrm{MST}, \mathrm{SPAD}, \mathrm{F}_{\mathrm{v}} / \mathrm{F}_{\mathrm{m}}$, PI e para interação frasco e genótipo, quanto às variáveis MST e SPAD (Tabela 1). Para as demais variáveis, foram constatadas diferenças significativas relacionadas aos fatores independentes luz ou genótipo.

As mudas de 'Vitória' apresentaram maior acúmulo de biomassa in vitro do que as mudas de 'IAC Fantástico', com os maiores valores de MFT e MST (Figura 1B, 1D), encontrados na luz branca para MFT, e na luz branca (Figura 1A, 1B) e frasco fechado para MST (Figura 1D). A cv. IAC Fantástico não apresentou diferença significativa quanto ao tipo de luz e frasco para MST (Figura 1C, 1D). Essa diferenciação no padrão de crescimento apresentado pelos genótipos é devido à divergência genética entre os parentais envolvidos nos cruzamentos (VENTURA et al., 2009).

A concentração da sacarose utilizada no meio de cultivo (15 e $\left.30 \mathrm{~g} \mathrm{~L}^{-1}\right)$ não proporcionou ganhos em biomassa quando se utilizou a luz vermelha e ventilaram-se os frascos de cultivo, visando a estimular um metabolismo fotoautotrófico dos explantes. Por outro lado, Mayak et al. (1998) relataram que, na concentração de $\mathrm{CO}_{2}$ ambiente, semelhante à utilizada neste experimento, a presença de açúcar no meio de cultivo aumentou a multiplicação in vitro do abacaxizeiro. No presente trabalho, a tentativa de tornar o ambiente fotoautotrófico, por meio da redução na concentração de sacarose $\left(15 \mathrm{~g} \mathrm{~L}^{-1}\right)$, a ventilação do frasco de cultivo com 380 ppm de $\mathrm{CO}_{2}$ e a utilização de luz vermelha não foram bem-sucedidas, na concentração de sacarose utilizada. Segundo Mayak et al. (1998), para o abacaxizeiro, a redução ou a eliminação da sacarose no meio de cultura somente foi possível quando houve incremento na concentração de $\mathrm{CO}_{2}$ para próximo de $1.000 \mathrm{ppm}$ de $\mathrm{CO}_{2}$, demonstrando a necessidade de associar a redução da sacarose a concentrações bem mais elevadas de $\mathrm{CO}_{2}$.

Em relação à intensidade da cor verde - SPAD (IV), verifica-se que houve um acúmulo significativo diferente de clorofila em função do tipo de luz, do genótipo e das interações luz x genótipo e frasco 
x genótipo (Tabela 1 e Figura 2). A luz vermelha contribuiu para maior intensidade de verde (IV) nas folhas de 'IAC Fantástico', não havendo diferença para a 'Vitória' (Figura 2). Quando comparamos os dois genótipos, a variável IV foi superior para 'Vitória'. Entretanto, para 'IAC Fantástico', e em luz vermelha, o incremento na concentração de clorofilas - IV, acompanhado do incremento na relação $\mathrm{F}_{\mathrm{v}} / \mathrm{F}_{\mathrm{m}}$ (Figura 3A) e no índice fotossintético (PI) (Figura 3B), não foi suficiente para estimular o crescimento neste genótipo (Figura 1). Torres-Netto et al. (2005 e 2002) mostraram que existe uma relação positiva entre o IV e o $\mathrm{F}_{\mathrm{v}} / \mathrm{F}_{\mathrm{m}}$ em algumas espécies. O genótipo 'Vitória' apresentou valores de $\mathrm{F}_{\mathrm{v}} / \mathrm{F}_{\mathrm{m}}$ superiores a 0,80, e o 'IAC Fantástico', valores entre 0,75 - 0,76 (Figura 3A). Esses valores estão dentro da faixa considerada ótima $\left(\mathrm{F}_{\mathrm{v}} / \mathrm{F}_{\mathrm{m}}\right.$ de $\left.0,800 \pm 0,5\right)$ por BolhàrNordenkampf et al. (1989), e este fato evidencia que, nos dois genótipos estudados, houve uma elevada capacidade do fotossistema II em absorver o fóton e reduzir a quinona $a$ (BOLHÀR-NORDENKAMPF et al., 1989); ou seja, houve elevada eficiência da maquinaria fotoquímica. Os valores da relação $\mathrm{F}_{\mathrm{v}} / \mathrm{F}_{\mathrm{m}}$ mostram que a maquinaria fotoquímica das plantas não foi alterada, quando as plantas estavam em um ambiente fotoautotrófico, associado à redução na concentração de sacarose para $15 \mathrm{~g} \mathrm{~L}^{-1} \mathrm{e}$ à ventilação dos frascos de cultivo.

O índice de vitalidade (PI) de uma planta pode ser caracterizado por meio do índice fotossintético. Esta variável, proposta por Strasser et al. (2000), é um índice que integra três componentes independentes: a densidade dos centros de reação ativos (RCs), a eficiência no transporte de elétrons após Qa ter sido reduzida e a probabilidade de que um fóton absorvido seja capaz de reduzir Qa. A variável PI mostra a atividade dos fotossistemas II e I e pode avaliar o desempenho da planta sob condição de estresse. Segundo os autores, esta variável pode efetuar uma avaliação da eficiência fotoquímica mais completa do que $\mathrm{F}_{\mathrm{v}} / \mathrm{F}_{\mathrm{m}}$, uma vez que PI envolve três componentes independentes. Contudo, neste trabalho com abacaxizeiro, as respostas foram semelhantes entre $\mathrm{F}_{\mathrm{v}} / \mathrm{F}_{\mathrm{m}}$ e PI (Figura 3A e 3B). Ao se correlacionar os dados de $\mathrm{F}_{\mathrm{v}} / \mathrm{F}_{\mathrm{m}}$ com PI (dados não mostrados), o valor da relação $\mathrm{F}_{\mathrm{v}} / \mathrm{F}_{\mathrm{m}}$ igual a 0,75 correspondeu a um valor de PI igual a 0,5 , mostrando que, para estas cultivares e nas condições de cultivo das plantas, este valor pode ser considerado como crítico. Os valores acima de 0,5 de PI demonstram alta eficiência na maquinaria fotoquímica. Essa variável apresentou efeito significativo para a interação genótipo $\mathrm{x}$ luz. A Figura 3B mostra que a variável PI foi afetada pelo tipo de luz utilizada, assim como $\mathrm{F}_{\mathrm{v}} / \mathrm{F}_{\mathrm{m}}$, apresentando respostas diferentes entre os genótipos. Para 'Vitória', não houve diferença quanto ao tipo de luz. Para a cv. IAC Fantástico, o maior valor de PI foi encontrado em luz vermelha.

Não houve assimilação fotossintética do carbono (A) in vitro em ambos os genótipos, quando se incidiu sobre as folhas uma intensidade de 300 $\mu \mathrm{mol} \mathrm{m} \mathrm{m}^{-2} \mathrm{~s}^{-1}$, independentemente do tipo de luz de cultivo (Figura 4). Não houve efeito significativo da sacarose nem do tipo de frasco de cultivo utilizado, mas o mesmo foi significativo para qualidade de luz e genótipo (Tabela 1). A luz vermelha pode ter contribuído para reduzir a respiração, o que permitiu menor liberação de $\mathrm{CO}_{2}$, mostrado pelos valores menos negativos de A (Figuras 4A e 4B). Esta resposta foi semelhante para 'Vitória', que apresentou valores de A menos negativos, ou seja, com menor taxa respiratória que a observada para 'IAC Fantástico'. Mayak et al. (1998) relataram que o abacaxizeiro assimilou duas vezes mais ${ }^{14} \mathrm{CO}_{2}$ quando a sacarose do meio foi eliminada, e que as atividades da Rubisco e da PEP-C foram muito maiores quando se removeu o açúcar do meio, na concentração de $380 \mathrm{ppm}$ de $\mathrm{CO}_{2}$. Outros trabalhos têm mostrado que a presença da sacarose no meio de cultivo pode reduzir a assimilação de $\mathrm{CO}_{2}$ (DESJARDINS et al., 1995). Diante disso, sugerese que, neste trabalho, a presença de sacarose no meio de cultivo pode ter sido o principal fator a não permitir a assimilação fotossintética do carbono, mesmo que as plantas tenham apresentado uma elevada eficiência fotoquímica do PSII. Em futuros estudos, com uso do ambiente fotoautotrófico in vitro, a injeção de $\mathrm{CO}_{2}$ a uma concentração maior que 380 ppm e a eliminação da sacarose do meio de cultivo, em associação à maior intensidade luminosa, podem ser uma importante estratégia para otimizar o incremento de biomassa das duas cultivares utilizadas neste estudo. 
TABELA 1 - Resumo da análise de variância dos fatores luz, tipo de frasco e genótipo com as interações em abacaxizeiro, aos 40 dias de cultivo in vitro.

\begin{tabular}{|c|c|c|c|c|c|c|c|}
\hline \multirow{2}{*}{ Fontes de Variação } & \multirow{2}{*}{ GL } & \multicolumn{6}{|c|}{ Quadrado Médio } \\
\hline & & MFT & MST & SPAD & $\mathbf{F}_{\mathrm{v}} / \mathbf{F}_{\mathrm{m}}$ & PI & $\mathbf{A}$ \\
\hline Luz & 1 & $0,18 * *$ & $0,40 * *$ & $617,91 * *$ & $0,13 * *$ & $0,12 * *$ & $58,84^{* *}$ \\
\hline Resíduo a & 4 & 0,18 & 0,45 & 11,40 & 0,26 & 0,47 & 1,12 \\
\hline Frasco & 1 & $0,11^{\mathrm{ns}}$ & $0,24^{\mathrm{ns}}$ & $4,06^{\mathrm{ns}}$ & $0,42^{\mathrm{ns}}$ & $0,27^{\mathrm{ns}}$ & $6,34^{\mathrm{ns}}$ \\
\hline Luz x Frasco & 1 & $0,21^{\mathrm{ns}}$ & $0,99^{\text {ns }}$ & $0,90^{\mathrm{ns}}$ & $0,14^{\mathrm{ns}}$ & $0,53^{\text {ns }}$ & $0,61^{\mathrm{ns}}$ \\
\hline Resíduo b & 4 & 0,17 & 0,75 & 17,00 & 0,17 & 0,10 & 3,86 \\
\hline Gen & 1 & $2,69 * *$ & $0,27 * *$ & $2442,73 * *$ & $0,15 * *$ & $8,13 * *$ & $410,61 * *$ \\
\hline Luz x Gen & 1 & $0,23^{\mathrm{ns}}$ & $0,39 * *$ & $142,89 * *$ & $0,24 * *$ & $1,54 * *$ & $11,14^{\mathrm{ns}}$ \\
\hline Frasco x Gen & 1 & $0,39^{\text {ns }}$ & $0,25 * *$ & $128,83 * *$ & $0,31^{\mathrm{ns}}$ & $0,21^{\mathrm{ns}}$ & $2,72^{\mathrm{ns}}$ \\
\hline Luz x Frasco x Gen & 1 & $0,16^{\mathrm{ns}}$ & $0,26^{\mathrm{ns}}$ & $1,52^{\mathrm{ns}}$ & $0,56^{\mathrm{ns}}$ & $0,11^{\mathrm{ns}}$ & $6,91^{\mathrm{ns}}$ \\
\hline Resíduo c & 8 & 0,29 & 0,72 & 25,88 & 0,27 & 0,18 & 9,09 \\
\hline Total & 23 & & & & & & \\
\hline CV Luz & & 27,27 & 72,25 & 28,18 & 33,33 & 28,48 & 22,81 \\
\hline CV Frasco & & 25,75 & 52,66 & 42,02 & 21,79 & 6,06 & 78,61 \\
\hline CV Gen & & 27,05 & 40,42 & 12,57 & 2,12 & 25,91 & 61,35 \\
\hline MÉDIA & & 0,66 & 0,62 & 40,45 & 0,78 & 1,65 & $-4,91$ \\
\hline
\end{tabular}

ns - Não significativo. ** ; * - Significativo pelo teste F, a 1\% e 5\% de probabilidade, respectivamente. CV (\%) - Coeficiente de Variação; Gen - Genótipo; Massa fresca total - MFT (g); Massa seca total - MST (g); Intensidade do verde - SPAD; Rendimento quântico máximo do fotossistema II - $\mathrm{F}_{\mathrm{v}} / \mathrm{F}_{\mathrm{m}}$; Índice Fotossintético - PI; Fotossíntese - $\mathrm{A}\left(\mu \mathrm{mol} \mathrm{CO}_{2} \mathrm{~kg}^{-1} \mathrm{~s}^{-1}\right)$.
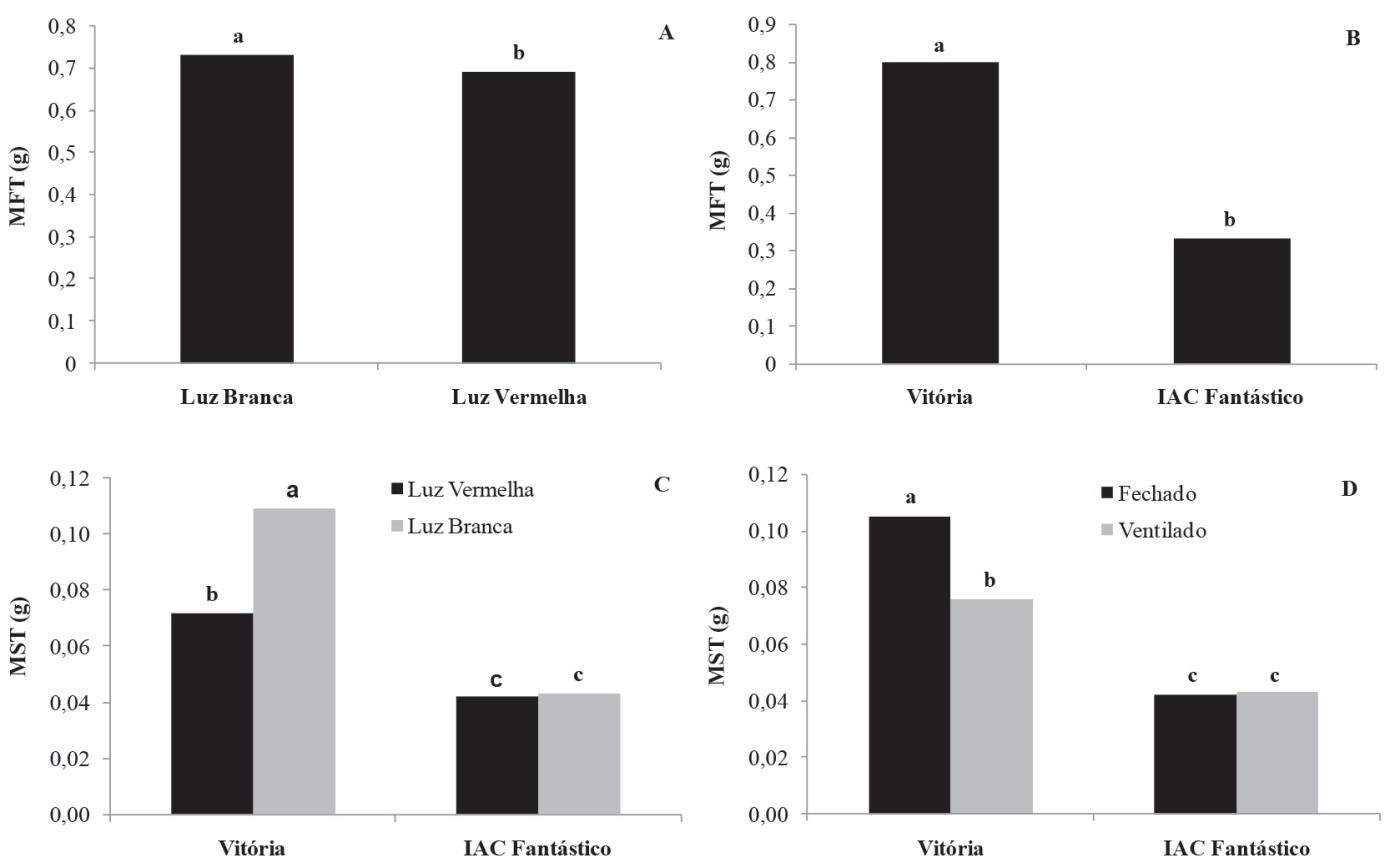

FIGURA 1 - Massa da matéria fresca e massa da matéria seca de mudas dos abacaxizeiros 'Vitória' e 'IAC Fantástico' após 40 dias de cultivo in vitro.

Médias seguidas por uma mesma letra não diferem estatisticamente, pelo teste de Tukey, ao nível de 5\% de probabilidade. 

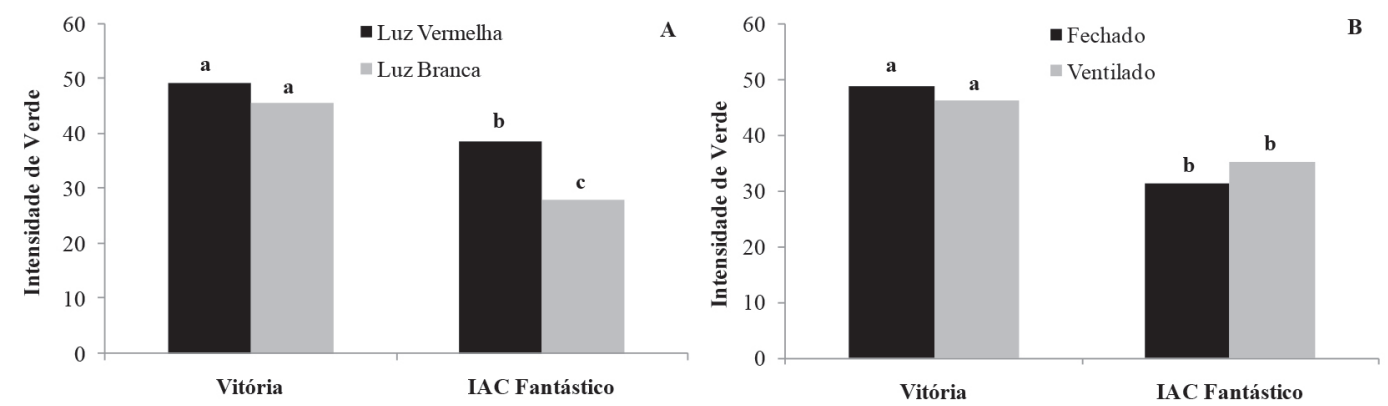

FIGURA 2 - Intensidade de verde em mudas dos abacaxizeiros 'Vitória' e 'IAC Fantástico' após 40 dias de cultivo in vitro.

Médias seguidas por uma mesma letra não diferem estatisticamente, pelo teste de Tukey, ao nível de 5\% de probabilidade.
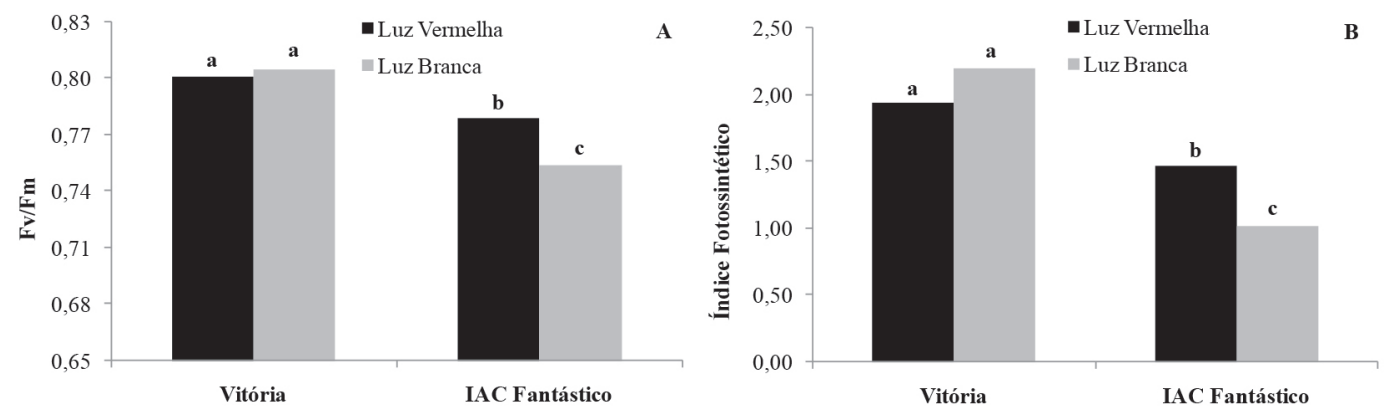

FIGURA 3 - Eficiência fotoquímica $\left(\mathrm{F}_{\mathrm{v}} / \mathrm{F}_{\mathrm{m}}\right)$ e Índice fotossintético (PI) de mudas dos abacaxizeiros 'Vitória' e 'IAC Fantástico' após 40 dias de cultivo in vitro.

Médias seguidas por uma mesma letra não diferem estatisticamente, pelo teste de Tukey, ao nível de 5\% de probabilidade.
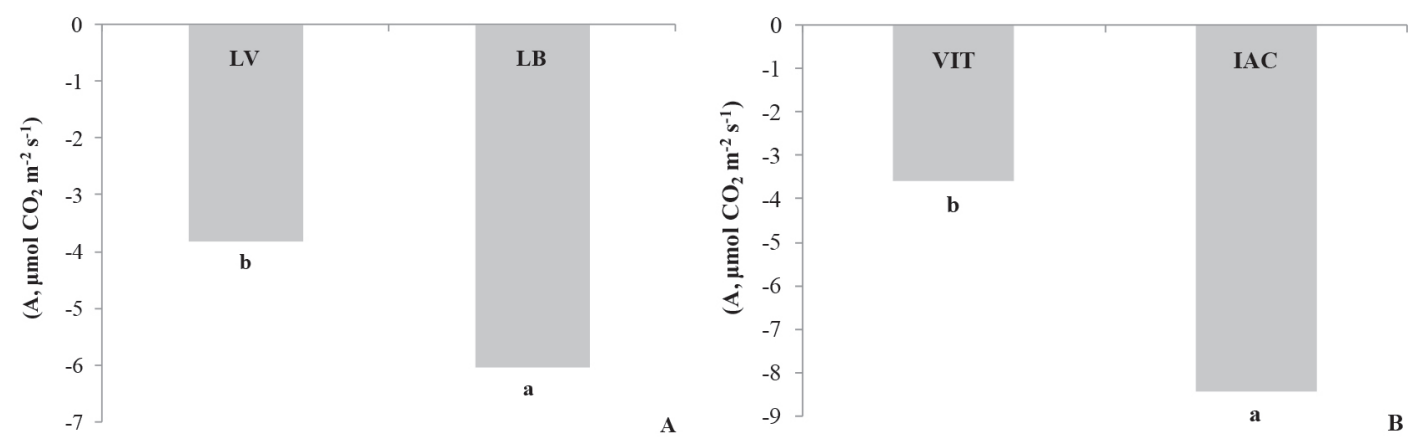

FIGURA 4 - Taxa fotossintética de mudas de abacaxizeiro em função do tipo de luz (A) e do genótipo (B), após 40 dias de cultivo in vitro. LV - Luz vermelha; LB - Luz branca, VIT - 'Vitória', IAC 'IAC Fantástico'.

Médias seguidas por uma mesma letra não diferem estatisticamente, pelo teste de Tukey, ao nível de $5 \%$ de probabilidade. 


\section{CONCLUSÕES}

1-Não é observada a assimilação fotossintética do carbono in vitro, independentemente da qualidade de luz utilizada e da adição de sacarose como fonte de carbono.

2-A cultivar IAC Fantástico, sob condição de luz vermelha, e em comparação à luz branca, apresenta maiores valores de intensidade verde das folhas (SPAD), de PI e do rendimento quântico máximo do PSII $\left(\mathrm{F}_{\mathrm{v}} / \mathrm{F}_{\mathrm{m}}\right)$, o que não é verificado para a cv. Vitória.

3-O genótipo 'IAC Fantástico' apresenta menor incremento de biomassa (crescimento) que o 'Vitória', sendo essa biomassa produzida por meio do carbono exógeno fornecido via sacarose aplicada ao meio de cultivo e, também, devido à variabilidade genética (genitores) dos dois genótipos ser diferente.

4-A ventilação dos frascos de cultivo, com aumento de trocas gasosas, não é suficiente para melhorar a competência fotossintética das duas cultivares avaliadas.

\section{AGRADECIMENTOS}

À FAPERJ e ao CNPq, pelo apoio à pesquisa; às empresas Biomudas e SBW do Brasil, pela disponibilização dos genótipos estudados.

\section{REFERENCIAS}

CABRAL, J.R.S.; MATOS, A.P.; JUNGHANS, D.T.; SOUZA, F.V.D. Pineapple genetic improvement in Brazil. Acta Horticulturae, The Hague, v.822, p.39-46, 2009.

CAMPOSTRINI, E.; TEIXEIRA, J.B.; CRUZ, A.R.R.; YAMANISHI, O.K. Efeito da concentração de $\mathrm{CO}_{2}$ e do teor de sacarose no crescimento de plântulas de abacaxi (Ananas comosus [L.] Merril) cultivadas in vitro. In: CONGRESSO BRASILEIRO DE FISIOLOGIA VEGETAL, 7., 1999, Brasília. Anais... Brasília: SBFV, 1999. v.11, p.33.

DAMIANI, C.R.; SCHUCH, M.W. Multiplicação fotoautotrófica de mirtilo através do uso de luz natural. Revista Brasileira de Fruticultura, Jaboticabal, v.30, n.2, p.482-487, 2008.
DESJARDINS, Y.; HDIDER, C.; RIEK, J. Carbon nutrition in vitro: regulation and manipulation of carbon assimilation in micropropagated systems. In: AITCHEN-CHRISTIE, J.; KOZAI, T.; SMITH, M.A.L. Automation and environmental control in plant tissue culture. Dordrecht: Kluwer Academic Publishers, 1995. p.441-471.

FUENTES, G.; TALAVERA, C.; DESJARDINS, Y.; SANTAMARÍA, J.M. Low exogenous sucrose improves ex vitro growth and photosynthesis in coconut in vitro plantlets if grown in vitro under high light. Acta Horticulturae, Wageningen, v.748, p.151-156, 2007.

KOZAI, T.; KUBOTA, C. Developing a photoautotrophic micropropagation system for woody plants. Journal of Plant Research, Saitama City, v.114, p.525-537, 2001.

MAYAK, S.; TIROSH, T.; ILAN, A.; DUVDEVANI, A.; KHAYAT, E. Growth and development of pineapple (Ananas comosus L.) plantlets cultured in vitro at enriched and ambient $\mathrm{CO}_{2}$ environments. Acta Horticulturae, Brisbane, v.461, p.225-229, 1998.

MURASHIGE, T.; SKOOG, F.A. A revised medium for rapid growth and bioassays with tobacco tissue cultures. Physiologia Plantarum, Copenhagen, v.15, n.3, p.473-497, 1962.

SAS INSTITUTE. Sas user's guide: statistics. Cary, 2003. 846p.

SPIRONELLO, A.; SIQUEIRA, W.J.; MARTINS, A.L.M.; USBERTI FILHO, J.A.; CARVALHO, C.R.L.; BETTIOL NETO, J.E.; SIGRIST, J.M.M.; FERRARI, J.T.; LOUZEIRO, I.M. Avaliação do Híbrido de abacaxizeiro IAC Fantástico visando à indicação de cultivo. In: SIMPÓSIO BRASILEIRO DE ABACAXIZEIRO, 4., 2011. Anais... 2011. CD-ROM.

STRASSER, R.J.; TSIMILLI-MICHAEL, M.; SRIVASTAVA, A. The fluorescence transient as a tool to characterize and screen photosynthetic samples. In: YUNUS, M.; PATHER, U.; MOHANLY, P. Probing photosynthesis: mechanisms, regulation and adaptation. London: Taylor and Francis, 2000. p.445-483. 
STRAUSS, A.J.; KRÜGER, G.H.J.; STRASSER, R.J.; VAN HEERDEN, P.D.R. Ranking of dark chilling tolerance in soybean genotypes probed by the chlorophyll a fluorescence transient O-JI-P. Environmental and Experimental Botany, Amsterdam, v.56, p.147-157, 2006.

TORRES NETTO, A.; CAMPOSTRINI, E.; OLIVEIRA，J.; BRESSAN-SMITH，R. Photosynthetic pigments, nitrogen, chlorophyll fluorescence and SPAD-502 readings in coffee leaves. Scientia Horticulturae, Amsterdam, v.104, n.199-209, 2005.

TORRES NETTO, A.; CAMPOSTRINI, E.; OLIVEIRA, J.G.; YAMANISHI, O.K. Portable chlorophyll meter for the quantification of photosynthetic pigments, nitrogen and the possible use for assessment of the photochemical process in Carica papaya L. Brazilian Journal Plant Physiology, Campinas, v.14, p.203-210, 2002.
VENTURA, J.A.; COSTA, H.; CABRAL, J.R.S.; MATOS, A.P. Vitória: new pineapple cultivar resistent to fusariosis. Acta Horticulturae, The Hague, v.822, p.51- 56, 2009.

XIAO, Y.; KOZAI, T. Commercial application of a photoautotrophic micropropagation system using large vessels with forced ventilation: plantlet growth and production cost. HortSciense, Alexandria, v.39, n.p.1387-1391, 2004. 